\title{
Hookworm disease and its relationship to capitalism and urban development
}

\author{
Leo Couacaud $^{1}$ \\ University of Mauritius, Mauritius
}

\begin{abstract}
The last one hundred years has seen a great deal of research on hookworm disease (Ankylostomiasis). But the literature is still characterized by a lack of consensus regarding the etiology of the disease and its patterns of transmission. Parasitologists still seem to disagree as to the perceived benefits of sanitation and footwear in reducing the incidence of infection. The relationship between urbanization and the decreasing incidence of infection, or alternatively the role of plantation work and human-manure-farming in the spread of hookworm disease, are still poorly understood or inadequately appreciated. This article proposes that behind most hookworm epidemics that have emerged in human history in the last one-hundred-to-two-hundred years, the constant factor has been density of population, not the type of occupation or agricultural work as has been proposed by some parasitologists. With the exception of human-manure-farming induced hookworm disease in China, which possibly dates back to ancient times and is transmitted by the use of human manure as a fertilizer, the outbreaks of hookworm disease that were documented in the mines of Europe and North America, the plantations of India and the Caribbean, and indigenous settlements in Australia at the turn of the twentieth century were due to changes promoted by capitalism and the concentration of larger numbers of people in confined areas that lacked appropriate sanitation. But as the article also shows, the decreasing incidence of hookworm infection in parts of the world where the disease was once rife seems to be related to increasing levels of urban development in these societies.
\end{abstract}

Key words: hookworm disease, defecation habits, population density, capitalist development, epidemics.

\section{Résumé}

Les cent dernières années ont vu une grande partie de la recherche sur la maladie de l'ankylostome. Mais la littérature est encore caractérisée par une absence de consensus sur l'étiologie de la maladie et ses modes de transmission. Les parasitologues débat encore les avantages perçus de l'assainissement et le port de chaussures dans la réduction de l'incidence de l'infection. La relation entre l'urbanisation et la réduction de l'incidence de l'infection, ou encore le rôle du travail de plantation et l'agriculture en utilisant du fumier humain dans la propagation de la maladie de l'ankylostome, sont encore mal compris ou mal apprécié. Je soutiens que derrière la plupart des épidémies ankylostome qui ont émergé dans l'histoire humaine dans les 100-200 dernières années, le facteur constant a été la densité de la population, pas le type de profession ou de travail agricole comme cela a été proposé par certains parasitologistes. À l'exception de l'agriculture utilisant l'engrais humain en Chine, qui a une longue histoire et transmet la maladie aux travailleurs agricoles, les foyers de la maladie ankylostome qui ont été documentés dans les mines de l'Europe et l'Amérique du Nord; les plantations de l'Inde et dans les Caraïbes; et établissements autochtones en Australie au début du XXe siècle ont été en raison de changements promus par le capitalisme et la concentration de grands nombres de personnes dans des espaces restreints qui ne disposaient pas d'installations sanitaires adéquates. Mais comme l'article montre aussi, l'incidence décroissante de l'ankylostomiase dans certaines parties du monde où la maladie était autrefois très commun semble être inversement proportionnelle au niveau de développement urbain dans ces sociétés.

Mots clés: ankylostomiase, les habitudes de défécation, la densité de la population, le développement capitaliste, les épidémies.

\footnotetext{
${ }^{1}$ Dr. Leo Couacaud, lecturer, Department of History and Political Science, University of Mauritius. Email: leocouacaud "at" gmail.com. I would like to thank Dr. Chip Colwell-Chanthaphonh for reading several drafts of this article and his thoughtful comments, and the reviewers and editor.
} 


\section{Resumen}

En los últimos cien años se ha visto gran cantidad de investigación sobre la enfermedad de anquilostoma (Anquilostomiasis). Sin embargo la literatura aún se caracteriza por la falta de consenso en relación a la etiología de la enfermedad y sus patrones de transmisión. Los parasitólogos todavía parecen estar en desacuerdo en relación a los beneficios percibidos por el saneamiento y calzado en la reducción de la incidencia de la infección. La relación entre urbanización y la disminución de la incidencia de la infección, o alternativamente el rol del trabajo en las plantaciones y el cultivo tratado con residuos orgánicos humanos en la propagación de la anquilostomiasis son aún poco conocidos o mal apreciados. Este artículo propone que detrás de la mayoría de las epidemias de anquilostomas que han surgido en la historia de la humanidad en los últimos cien a doscientos años, el factor constante ha sido la densidad poblacional, no el tipo de ocupación o el trabajo agrícola como ha sido propuesto por algunos parasitólogos. Con la excepción de la agricultura con abono humano, la que indujo la anquilostomiasis en China, la cual posiblemente se remonta a tiempos antiguos y es transmitida por el uso de abono humano como fertilizante, los brotes de la anquilostomiasis que fueron documentados en las minas de Europa y América del Norte, las plantaciones de India y el Caribe, y los asentamientos indígenas en Australia a comienzos del siglo XX se deben a modificaciones promovidas por el capitalismo y la concentración de gran número de personas en áreas confinadas que carecían de saneamiento apropiado. Pero como el artículo también muestra, la disminución de la incidencia de la infección de anquilostomiasis en partes del mundo donde la enfermedad fue alguna vez abundante pareciera estar relacionada con el aumento de los niveles de desarrollo urbano en estas sociedades.

Palabras claves: enfermedad de anquilostoma (Anquilostomiasis), hábitos de defecación, densidad de población, desarrollo capitalista, epidemias.

\section{Introduction}

Archaeo-parasitological studies show that hookworms have infected humans for thousands of years (Gonçalves et al. 2003). But most of the major outbreaks of the disease were documented at the turn of the twentieth century. After its initial discovery in the second half of the nineteenth century, parasitologists went about documenting the geographical spread of the disease and devised a number of methods to determine its patterns of transmission and the severity of infection. Confined for the most part to tropical and subtropical climates, parasitologists were able to document a number of hookworm epidemics in range of localities including former British tropical colonies, Europe and North America, as well as China and indigenous settlements in Australia. With the exception of China's well-documented cases of human-manure-farming induced hookworm disease, which is transmitted by the use of human manure as a fertilizer, the outbreaks of hookworm disease that were documented in the mines of Europe and North America, the plantations of India and the Caribbean, and indigenous settlements in Australia at this time were considered to be the result of soil pollution and inadequate sanitation. Having established these two basic modes of transmission, and the symbiotic relationship between Ancylostoma duodenale and Necator americanus and their human hosts, both of which require faeces to propagate and are the only known hookworm species to infect human beings, parasitologists suggested that certain occupations seemed to promote ideal conditions for the spread of the disease.

The cogency of these insights remains poorly understood or has gone unquestioned in subsequent studies of hookworm disease by parasitologists. Fleeting references are occasionally made to Asa Chandler's (1929) classic study of hookworm disease, or the postulated relationship between the spread of the disease and plantation agriculture. However, more recent studies have added little to our knowledge of the epidemiology of hookworm disease and demonstrate a lack of familiarity with the older literature and in some cases go back over well-trodden ground. What I propose to do in this article is to review the older literature on hookworm disease and compare it to more recent parasitological studies in order to clarify the role that certain occupations are said to play in the spread of the disease and its relationship to economic development. In contrast to the conventional wisdom, I argue that the major outbreaks of hookworm disease that were documented at the turn of the twentieth century (but not China's cases of human-manure-farming induced hookworm disease) were a result of changes promoted by capitalism and concentrations of larger numbers of people in confined areas lacking appropriate sanitation, rather than any specific occupations. To 
this effect, I draw upon the insights of evolutionary anthropologists and the links they have established between population density and increased suspectibility to infectious diseases, and also propose that the decreasing incidence of hookworm infection in parts of the world where the disease was once rife seems to be related to greater levels of urban development in these societies.

\section{Adopting an interdisciplinary approach to hookworm disease}

This would not be the first time that someone has called for an interdisciplinary approach to the study of an infectious disease. The study of infectious diseases, perhaps to an extent unparalleled in any other domain of scientific inquiry, has drawn interest from a wide-range of researchers in the humanities and social sciences. Historians, anthropologists, geographers, and archaeologists have all demonstrated an interest in the study of infectious diseases, although their modus operandi and stated objectives may differ. For example, anthropologists and historians have shown a particular interest in elucidating a contextualist approach to the study of infectious diseases, while geographers and archaeologists have demonstrated a more pronounced proclivity for pursuing what one might describe (for want of a better word) as a positivist approach. Needless to say, one cannot lump all anthropologists and historians together and suggest that they are only interested in getting at the social meaning, or elucidating the response of elites and non-elites, to the spread of infectious diseases. However, it is evident that a number of anthropologists and historians who are interested in the study of infectious diseases evince an extreme social constructivist approach that seems less interested in advancing our knowledge of how infectious diseases are spread (see Marks 1997; Patterson 1998) and in some cases even explicitly profess an "anti-foundationalist" approach (Anderson 1995; Anderson 1998).

Just why the study of infectious diseases has drawn so much interest from researchers in disciplines whose traditional subject matter is human behaviour rather than germs is perhaps a question that deserves further consideration. However, what does seem clear is that there have been mounting calls for an interdisciplinary approach to the study of infectious diseases in view of the benefits that the research methods of disciplines in the humanities and social sciences can potentially bring to this subject matter. Jacques M. May (1958) is roundly recognized for his early pioneering work in "disease ecology" and advocated combining medical and social scientific approaches to better understand the infectious diseases that affect human beings. As a geographer, May was sensitive to the manner in which human beings interact with their environment and recommended the anthropological concept of culture to theorize how human behaviour may unintentionally spread infectious diseases. Since May's early pioneering work, a number of other social scientists have drawn our attention to the importance of taking into account how economic development can also contribute to the spread of infectious diseases (Hughes and Hunter 1970; Turshen 1977; Inhorn and Brown 1990; Mayer 1996). A noteworthy example in this respect is the work of Charles C. Hughes and John M. Hunter (the former an anthropologist and the latter a geographer) who explored the relationship between development projects and the spread of malaria and schistosomiasis in Africa. According to Hughes and Hunter (1970), the construction of dams and irrigation schemes in Africa have provided ideal conditions for the reproduction of the snails and mosquitos that act as vectors for the transmission of these diseases, proposing they be viewed as examples of "diseases of development" or "developo-genic diseases".

To date, though, we have not heard similar calls for an interdisciplinary approach to the study of hookworm disease. This is surprising because the external phase of the lifecyle of the parasites that cause the disease by drawing blood from the small intestine and require human faeces and soil to propogate before the hookworm larvae can reinfect their hosts, ${ }^{2}$ make them particularly amenable to observation. ${ }^{3}$ Equally surprising is the lack of interest that the subject has generated among anthropologists in view of the contribution that the discipline's concepts and research methods can make to the study of the epidemiology of hookworm disease. ${ }^{4}$ Although May employs a circumscribed and at times confusing concept of culture, his

\footnotetext{
${ }^{2}$ Iron deficiency anemia is the primary symptom of hookworm disease. However, in addition to reducing the immune system's ability to resist attacks by other diseases, the disease is also believed to retard growth and mental development and have adverse health effects on pregnant women (see Brooker et al. 2004).

${ }^{3}$ Ancylostoma duodenale and Necator americanus can vary in length but usually do not exceed $10-12 \mathrm{~mm}$, with females attaining larger proportions than males in both species of hookworms. However, they generally remain invisible to the naked eye because of their extremely narrow diameter (see Chandler 1929: 67-79).

${ }^{4}$ A notable exception is the work of Schad et al. (1983).
} 
brief ruminations on the connection between defecation habits and hookworm disease in The ecology of human disease points to the obvious benefits of the culture concept to the study of infectious diseases. Yet well before May, Chandler wrote what is still the most comprehensive study of hookworm epidemiology and pathology in the literature, and offers an even more insightful review of the relationship between defecation habits and the spread of hookworm disease in Hookworm disease: its distribution, biology, epidemiology, pathology, diagnosis, treatment and control (1929). Of particular interest are the inferences Chandler is able to make with respect to how age, gender, and cultural background, can determine exposure to hookworm infection based on his observations of people's defecation habits in India. As his observations illustrate, people who defecate in the open do not do so indiscriminately or promiscuously as is often claimed in the hookworm literature, but usually seek some form of privacy, especially if they are adults; whereas it is small children who are less self-conscious about where they defecate and do so "indiscriminately" and "promiscuously". As we shall see, this insight has important consequences for understanding the epidemiology of hookworm disease, because the tendency of adults to seek out well-known or convenient defecation sites in part for the privacy they offer further compounds infection rates.

Besides parasitologists and archaeo-parasitologists, historians have arguably done the most extensive research on hookworm disease. For their part, historians have focused on researching various outbreaks of hookworm disease around the world - particularly the early twentieth century hookworm control campaigns funded by the Rockefeller Foundation in tropical British colonies with plantation sectors (Hewa 1994; Pemberton 2003; Palmer 2009, 2010). But it is here that we encounter the limitations of contextualist approaches that seem less interested in trying to advance our knowledge of the epidemiology of hookworm disease, and more preoccupied with criticizing ruling elites for failing to improve the lives of those suffering from the disease. I am not suggesting there is no room for this sort of critique; however, it seems misguided only to condemn colonial officials and plantation owners for failing to prevent the spread of hookworm disease because they did not do enough to improve sanitary conditions in these British colonies, when providing latrines does not always lead to an immediate reduction in infection rates, and if we also consider the logistical difficulties involved in promoting these sorts of changes in agrarian societies at the turn of the twenteith century. Historians such as Soma Hewa (1994) and Rita Pemberton (2003) over-speculate on the motivations of colonial officials and plantation owners rather than adequately describe what working and living conditions were like in these British colonies at the time. Had they done so, they would have discovered in former British colonial plantation societies such as Sri Lanka and Mauritius, sanitary conditions in villages and plantations were quite similar (Couacaud 2011; cf. Philips 1955). Thus, one cannot level the blame for the spread of hookworm disease solely on the inaction of plantation owners and colonial officials.

While one may criticize historians for failing to pursue these lines of inquiry, many parasitological studies seem unnecessarily restrictive in scope and could benefit from adopting a historical approach to the study of the epidemiology of hookworm disease. For example, in Hookworm disease: current status and new directions, several contributors who wrote on the status of hookworm infection in Latin America and the Caribbean (Naquira 1990) and Australasia (Carroll and Walker 1990) fail to consider earlier studies carried out in these regions. In both regions, outbreaks of hookworm disease were documented among plantation labourers and indigenous peoples who were forced onto settlements at the beginning of the twentieth century. Comparing the earlier literature with the more recent studies cited by Naquira (1990) and Carroll and Walker (1990) would have allowed them to more adequately assess the extent to which infection rates have declined in these regions and for what reasons. The benefits of adopting a historical approach can be illustrated by comparing Sen-Hai and Wei-Xia's (1990) chapter on the status of hookworm infection in China, a country notorious for having high rates of infection from the use of human manure in farming, with a more recent article by Peter J. Hotez (2002). According to Sen-Hai and Wei-Xia, the principal reason that hookworm infection rates declined in China between the 1950s and 1980s was due to government-backed control programmes. However, since the 1990s economic development has accelerated in China, particularly in the eastern coastal provinces and cities. As Hotez (2002: 1036; cf. Fenghua et al. 1998) shows, this development has had a spill-over effect in rural provinces such as Jiangsu located next to the city of Shanghai, with infection rates halving in ten years. 
In Hotez's view, economic development has done more to reduce the incidence of hookworm disease than any one single factor, particularly in industrialized nations such as the United States and South Korea that once struggled with the disease. But it is important not to confuse this insight with Thomas McKeown's (1976) thesis that rising living standards, rather than advances in medical science, are the principal reason for the decline in communicable diseases. While preventive medical interventions of the sort initiated by the Rockefeller Foundation may not have eradicated the disease but certainly helped to contain it, it is not so much rising living standards but the improvements that we have come to associate with urban development such as regularly wearing shoes, living in houses with wooden or concrete flooring, and using toilets connected to waste disposal systems that have largely been responsible for reducing the incidence of hookworm infection. For Hotez the persistence of hookworm infection serves as a useful marker of poverty, leading him to question if "poverty creates conditions that are favourable for hookworm transmission ... or whether hookworm itself also contributes to low human economic productivity" (2002: 1037). One could, however, just as easily argue that the eradication of hookworm disease can serve as a useful measure of urban development, as is reflected not only in its eradication from industrialized nations but in former British colonial plantation societies in the Caribbean and the Indian Ocean island of Mauritius, which is now classified as a middle income country and is no longer concerned about hookworm disease (cf. Couacaud 2011; Mohith et al. 2011).

In any case, the questions that Hotez (2002, 2008) has raised are the sorts of questions that other parasitologists might consider when investigating the epidemiology of hookworm disease rather than unduly focusing on isolated variables that do not provide us with a sufficiently clear picture of how infection is transmitted. Parasitologists usually focus on documenting the incidence and intensity of hookworm infection rates in their surveys, and proposing curative measures to reduce the sources of infection. In addition to proposing curative measures, they sometimes seek to determine how hookworm infection is transmitted amongst the communities or population groups that they study. This typically involves isolating a number of variables such as age, gender, socio-economic status, and the presence or absence of latrines, and determining if any correlations can be established between these variables and rates of hookworm infection in the community under study. It is this aspect that often leaves much to be desired, not only because many of these studies demonstrate a lack of familiarity with the older literature on hookworm disease and go back over well-trodden ground. But also because some of these studies fail to consider such simple things as the defecation habits of the study group, and employ a synchronic approach that it is not sufficiently mindful of the time passing on their results. These limitations are reflected in the continuing debate over whether sanitation and footwear can be shown to reduce hookworm infection rates (Chongsuvivatwong et al. 1996; Esrey et al. 1991; Olsen et al. 2001; Sorensen et al. 1994), or if clay soil inhibits hookworm larvae development (Saathoff et al. 2005) - even though these issues seem to have been satisfactorily dealt with in the older literature by early research pioneers like Chandler (1929: 150-161, 193-211). ${ }^{5}$

It is when we compare the various outbreaks of hookworm disease that were documented in different parts of the world at the turn of the twentieth century, and search for an underlying cause, that the benefits of an inter-disciplinary approach become clearer. Upon comparing the outbreaks of hookworm disease that were documented in the mines of Europe and North America, the plantations of India and the Caribbean, and indigenous settlements in Australia ${ }^{6}$ - but not China's cases of human-manure-farming induced hookworm disease - what is striking about all of these epidemics is that they occurred at roughly the same time in different localities where large numbers of peoples came together as a result of changes wrought by capitalist

\footnotetext{
${ }^{5}$ There seems to be little disagreement that clay and compact earth inhibit the development of hookworm larvae, while loose soil and sand (if they are sufficiently moist) are highly conducive to their propogation. The debate as to whether sanitation and footwear can be shown to reduce hookworm infection rates is more complicated, with one study (Olsen et al. 2001: 579) proposing differences between defecation habits in private and public domains may account for the varying results in these studies. But as Bradley et al. (1993:1 47) point out, one must wait a considerable period of time before the benefits of sanitation are fully realized, which to me suggests that studies that seek to quantify the relation between sanitation and hookworm infection rates must do a better job of assessing temporal change by measuring these variables both before and after sanitation or footwear have been introduced in the study groups.

${ }^{6}$ I chose these examples because they are sufficiently representative of the different types of hookworm epidemics that emerged around the world at the turn of the twentieth century. The exception are the outbreaks of hookworm disease that were documented in indigenous settlements in Australia, which perhaps received less attention in the annual reports of the Rockefeller Foundation because they did not pose a direct threat to the economic interests of capitalists.
} 
forms of development, and where sanitary conditions inevitably proved wanting. Hence in contrast to the more common explanation that soil pollution is the main cause of hookworm disease (Cort and Payne 1922a, 1922b; Chandler 1929), or that hookworm disease is an "occupational disease" (Chandler 1929; Chang et al. 1949; Cort 1918; Cort et al. 1926; Smillie 1922; Sawyer 1924) and/or associated with certain types of agricultural work (Cort et al. 1923a, 1923b, 1923d; Pawlowski et al. 1991), what all of these different but related outbreaks of hookworm disease suggest is that economic development has an effect on the spread of infectious diseases. Such a 'political ecology of health' approach requires not only taking into account how the working and living conditions of the affected populations were transformed by capitalist forms of development but also the extent to which a sedentary lifestyle and greater population densities proved conducive to the spread of hookworm disease in the absence of adequate sanitation.

Evolutionary anthropologists have been instrumental in drawing our attention to the importance of studying the relationship between population density and the spread of infectious diseases. In an article summarizing some of the most important developments in this field, Armelagos and Dewey (1970) pointed out that it is with the transition from a mobile hunter-gathering to a sedentary agricultural lifestyle that infectious diseases began to pose more of a direct threat to human populations. For most of human history, humans lived in small bands following a hunter-gathering lifestyle, and it is only relatively recently and with the advent of agriculture that people settled in larger numbers in confined areas exposing them to greater risk of contact with infectious diseases. A related problem that became particularly acute with industrialization and population increases in cities was how to dispose of human waste, which often finds it way into the water supply and causes severe health problems, as reflected in the cholera epidemics of the nineteenth and twentieth centuries. Although hookworm disease primarily occurs in rural settings, ${ }^{7}$ a comparison of the various outbreaks that were documented at the turn of the twentieth century shows that concentrations of larger numbers of people in confined areas and difficulties in disposing of human waste were also the principal causes of these epidemics. And, in most cases, these epidemics were the result of capitalist development such as industrial mining and plantation agriculture, which promoted changes that proved conducive to the spread of hookworm disease, due to the demand for cheap and plentiful supplies of labour and the failure to meet the sanitary requirements of these populations. However, when comparing indigenous settlements in Australia, it is important to bear in mind that while these settlements were not explicitly established with the purpose of transforming the indigenous population from hunter-gatherers into a sedentary workforce, the epidemiological effect was the same because they were forced into confined areas that lacked appropriate methods to prevent the outbreak of the disease.

In the remainder of the article, I review the major outbreaks of hookworm disease that were documented at the turn of the twentieth century in order to demonstrate that these epidemics were the result of changes promoted by capitalism. Before I proceed to do this, however, I begin by discussing China's experience with cases of human-manure-farming induced hookworm disease to determine what distinguishes it from the outbreaks that occurred in other parts of the world at the turn of the twentieth century. It is widely thought that China has been grappling with hookworm disease for many centuries, or as long as human manure has been used as a fertilizer, whereas it is my argument that the outbreaks of hookworm disease that were documented in other parts of the world at the turn of the century were a result of changes promoted by capitalism and the concentration of larger numbers of people in confined areas lacking appropriate sanitation. After this, I describe in more detail the outbreaks of hookworm disease that were documented at the turn of the twentieth century in the mines of Europe and North America, the plantations of India and the Caribbean, and indigenous settlements in Australia. Drawing upon the available literature, I show that in each case these outbreaks resulted from changes promoted by capitalism and the concentration of larger numbers of people in confined areas and the failure to meet the sanitary needs of these populations. However, I should also add that what Australia's indigenous settlements demonstrate is that while capitalism has helped to spread hookworm disease, the disease can spread without capitalist development so long as the population is dense enough and sanitary conditions unsatifactory.

\footnotetext{
${ }^{7}$ While some studies do point to cases of hookworm infection in periurban and slum housing areas (Brooker et al. 2006; Desowitz et al. 1961; Ngonjo et al. 2012), the infection rates appear to be less significant than in rural areas and is probably related to the absence of sufficiently loose soil and the other kind of environmental conditions hookworm larvae typically require to propagate.
} 


\section{Human-manure-farming in China}

The primary difference between China's experience with hookworm disease and the outbreaks that were documented in other parts of the world at the turn of the twentieth century is that China has seemingly been grappling with this problem for many centuries, whereas it is most probably a recent development in the other regions of the globe. As a number of studies have demonstrated (Chang et al. 1949; Cort et al. 1926; Tang 1949), hookworm disease in China is typically associated with the use of human manure as a fertilizer in agricultural cultivation and it is widely thought that this is a centuries old tradition (cf. King 1911). Cort et al. (1926) were the first parasitologists to conclusively establish a link between the use of human manure in agricultural cultivation and the spread of hookworm disease in China, proposing that seri-culture (or the cultivation of mulberry trees (Morus spp.) accounted for its prevalence in central and southern China and that the climate was too cold in northern China for the disease to spread. However, Chang et al. (1949) subsequently showed that the prevalence of the disease in the southwestern province of Sichuan was not related to the cultivation of mulberry trees but depended upon the "method of cultivation" or how frequently human manure was applied to agricultural crops and at what times of the year.

These findings were echoed in another study conducted shortly afterwards in the southeastern province of Fujian by Tang (1949), which also demonstrated that the cultivation of sweet potatoes (Ipomoea batatas) was the most important means of the transmission in this province. Chang et al.'s Hookworm disease in Szechwan Province, West China provides a useful overview. Their surveys demonstrates that the intercropping of corn and sweet potato, rather than cultivation of mulberry trees, was instrumental in the spread of hookworm disease in Sichuan due to a number of factors that included more regular application of human manure - and at the beginning of the growing season when rain was more plentiful and infective larvae were present in larger numbers. ${ }^{8}$ Sichaun apparently enjoys favourable conditions for the propogation of hookworms and the authors documented a "rather high incidence ... [but] moderately low degree of hookworm infection" among mulberry trees farmers - whereas among corn and sweet potato farmers both the incidence and intensity of infection were much higher (Chang et al. 1949: 30). According to Chang et al., these conditions conspired to produce hookworm infection rates in Sichuan's farming districts that were frequently over $90 \%$, while the intensity of infection was also very high with many adults registering egg counts over 3,000 per gram. Chang et al. documented numerous cases of patients suffering from clinical signs of hookworm disease, as reflected in both low haemoglobin levels and the pervasiveness of anemia, which they suggest was exacerbated by poor nutrition and lack of protein in the typical Chinese farmer's diet (1949: 17). ${ }^{9}$ Cases of ground itch were also in evidence and became particularly noticeable after sweet potato vines were transplanted from nursery beds to the fields at the beginning of the growing season during times of high rainfall. Finally, Chang et al. (1949: 17, 114) point out that in comparison to other parts of the world where hookworm infection is normally transmitted by soil pollution and lack of footwear, for humanmanure-farmers infection is transmitted via contact with both feet and hands because of the manuring methods Chinese farmers use.

Upon comparing the results of Chang et al.'s surveys with more recent surveys of hookworm infection in China, it is surprising how widespread the problem still is in many parts of the country. A national survey of helminth infections in China conducted between 1988-1992 showed that approximately 17 per cent of the population, or 194 million people, were infected by hookworm, a majority of whom were concentrated in China's rural provinces where the use of human manure is still common (Long-Qi et al. 1995). In a follow-up survey conducted in 1997 in Sichuan province, Changhua et al. (1999) determined that in some farming districts hookworm infection rates had not substantially decreased since Chang et al.'s surveys fifty years ago, and that intensity rates had even increased. The survey compared two different farming districts in Sichuan and discovered the main source of hookworm infection in one of the farming districts was related to the cultivation of corn and sweet potato and the continuing use of human manure to fertilize agricultural crops. Changhua et al. (1999: 248) also discovered that the prevalence of hookworm infection in these Sichuan farming districts increased with age, suggesting to them that the higher incidence of infection among

\footnotetext{
${ }^{8}$ Chang et al. (1949: 83-85) concur, however, with Cort et al.'s finding that rice cultivation did not promote the spread of hookworm infection because hookworm larvae are unable to survive in deep or standing pools of water.

${ }^{9}$ Chang et al. (1949: 20-21) point out that even those indivudals who had readings of less than 3,000 eggs per gram also suffered from clinical signs of the disease that they linked to poor diet and nutrition.
} 
the elderly may point to changing demographic patterns in rural China as young immigrants move to urban areas in search of work while the elderly remain in agriculture. Hotez, one of the contributors to the study by Changua et al. (1999), has concluded from these findings that China faces the prospect of an ageing rural population more suspectible to hookworm infection than any other section of the population and that control programs may need to more aggressively target this group in the future (Hotez 2002: 1034-1035).

It is in the same article that Hotez claims that economic development has done more to reduce the incidence of hookworm infection than any single factor and also queries its relationship to poverty in China. The basis of Hotez's claims derive from a correlation he established between hookworm infection rates in China and per capita GDP figures for the nation's different provinces. According to these figures, China's wealthiest provinces have the lowest infection rates, while China's poorest provinces "have the highest rates of hookworm" (Hotez 2002: 1037). However, as I alluded to earlier, it is important not to confuse this insight with Thomas McKweon's (1976) thesis that rising living standards, rather than advances in medical science, has been the principal cause of the decline in communicable diseases in the industrialized world. Hotez does not suggest there are parallels between his findings and the "McKweon thesis", ${ }^{10}$ but my concern is that in arguing that the decreasing incidence of hookworm infection can be reduced to "economic development" writ large, Hotez (2002: 1036-1037) is diverting our attention from a more reliable method of measurement: levels of urban development. Urban and economic development are undoubtedly related, and in most cases are synoymous with each other, but economic development need not always translate into urban development. It is only with the latter that we are likely to see the eradication of the kind of conditions that make it impossible for this soil-dependent parasite to survive. As I show in the following sections, focusing on urban indices such as regularly wearing shoes, living in houses with wooden or concrete flooring and using toilets connected to waste disposal systems, offer a more reliable way of determining if hookworm infection will come to constitute a public health problem.

Related to this issue is the more vexing question of just how long the Chinese population has been suffering from hookworm disease. Chang et al. (1949: 2), for example, claim that hookworm disease in China dates back to ancient times, but do not furnish any archaeological or archival evidence to substantiate this claim. This claim appears to be predicated on several assumptions:

1) Chinese civilization is an ancient one and owes much of its success to agriculture;

2) Seri-culture, or the cultivation of mulberry trees and the production of silk, has an equally long history in China where it first began;

3) It is widely thought that the use of human manure as an agricultural fertilizer is a centuries old tradition.

However, as Chang et al. (1949: 17) point out, the introduction of the sweet potato to China is of relatively recent origins and had been introduced to Sichuan not long before commencing their research. ${ }^{11}$ Hence if the spread of hookworm disease has been linked to the cultivation of sweet potatoes by Chang et al. (1949) in Sichaun, and by Tang (1949) in Fujian, it is possible that in these provinces hookworm disease only became a public health problem comparatively recently. This, in turn, may warrant a review of the terminology used by parasitologists to describe hookworm infection rates in some Chinese provinces in the first half of the twentieth century as "endemic" (Cort et al. 1926; Chang et al. 1949; Tang 1949). The rationale for employing this terminology, and not describing high infection rates in the Chinese provinces that cultivated sweet potatoes as epidemics, is most probably related to another assumption, which is that rates of hookworm infection have remained consistently high in these provinces for an extended period of time. But if parasitologists are uncertain as to how long methods of agricultural cultivation linked to hookworm disease have been practiced, it may pay to investigate how old the intensive farming of sweet potato cultivation actually is in these provinces. ${ }^{12}$

\footnotetext{
${ }^{10}$ See Szreter (1988) for a compelling refutation of some of the most basic premises of the "McKweon thesis."

${ }^{11}$ According to Thiesen (2006) the sweet-potato was most likely introduced to China from the Americas in the 1500 s.

${ }^{12}$ In determining what criteria to use to describe a disease outbreak as an epidemic, Green et al. (2002) point out that this requires quantifying the incidence of the disease, determining the location of the outbreak, and specifying a time-frame.
} 


\section{Industrial mining in Europe and North America}

The foregoing discussion raises several issues that need to be borne in mind in distinguishing humanmanure-farming induced hookworm disease in China from the outbreaks that were documented in other parts of the world at the turn of the twentieth century. While there may be grounds for problematizing the claim that hookworm disease in China dates back to ancient times, it would appear that Chinese farmers have been suffering from the disease for a long period of time, particularly insofar as the cultivation of mulberry trees and the use of human manure to fertilize these trees is concerned. Whereas I have suggested that the outbreaks of hookworm disease documented in other parts of the world at the turn of the twentieth century are most probably a recent development, and are unlikely to have predated the expansion of capitalist forms of development associated with earlier stages of industrial intensification such as industrial mining and plantation agriculture.

The reason I say this is because, as I pointed out earlier, hookworm disease proliferates when the population is sufficiently large or dense enough for the disease to more easily spread and there are ensuing difficulties disposing of human waste, and we know that labor-intensive industries such as mining and plantation agriculture promoted these sorts of changes. ${ }^{13}$ For instance, if we are to take the coal mining industry as an example, it did not become fully industrialized in Britain until the middle of the nineteenth century, and prior to its industrialization it was largely restricted to individuals or small teams working in shallow pits and narrow shafts (Mitchell 1984; cf. Hobsbawm 1968). ${ }^{14}$ Similarly, slave plantations in the Americas were predominantly family-owned enterprises that relied on comparatively small labour forces and did not undergone any significant form of industrial expansion until the middle of the nineteenth century (Schnakenbourg 1984; cf. Mintz 1956). ${ }^{15}$ Both industries also had problems disposing of human waste; but as we shall see, in industrial mining hookworm infection primarily affects underground workers when sanitation is inadequate and the climate conducive to the propogation of infective larvae, while in plantation agriculture exposure to hookworm infection is not restricted to working in the fields but also depends on the defecation habits of workers close to where they reside.

The construction of the St. Gotthard tunnel between 1879 and 1880 in the European Alps led to the first recorded outbreak of hookworm disease in Europe, and was quickly connected to other outbreaks in mines in continental Europe and the British Isles. Infection rates amongst miners (and brick workers) in Europe tended to vary depending on local conditions, ${ }^{16}$ but it is from the Cornish tin mine of Dolcoath that some of the most detailed parasitological studies of hookworm disease have been made available. In a series of studies that was prompted by a British parliamentary inquiry into the state of Cornish mines, Boycott and Haldane (1903, 1904, 1909) established that "Dolcoath" or "miner's anemia" was not related to poor ventilation or bad air as had previously been thought, but hookworm disease. Based on surveys carried out between 1903 and 1904, the authors discovered that 94\% of the workforce was infected, numerous miners had worryingly low haemoglobin levels, and severe skin eruptions described by the miners as the "bunches" were common. But in contrast to other cases of hookworm dermatitis (or "ground itch") that normally affect the feet of plantation workers, and both the feet and hands of human-manure-farmers, it was the buttocks, knees and forearms of the Dolcoath miners that were exposed to infection. The principal cause of the outbreak of hookworm disease in the Dolcoath mine was said to be soil pollution, as miners were accustomed

\footnotetext{
${ }^{13}$ According to Chandler (1929: 182-186) the type of plantation crops best suited to the spread of hookworm disease include sugar, coffee, tea, cacao, banana and rubber. Other crops such as rice, jute, cotton and wheat are less suitable. This is because the former are planted in areas where there are higher rainfall levels and the climate more humid, and both the type of crops and soil promote retention of moisture suitable for the propagation of hookworm larvae.

${ }^{14}$ For the coal industry, Eric Hobsbawm (1968: 116) states: "In 1850 there were rather more than 200,000 [miners] ... in Britain, around 1880 about half a million, and by 1914 well over 1.2 million, working in some three thousand mines, or almost as many as the entire agricultural population and the (male and female) textile workers."

${ }^{15}$ If we restrict our analysis to the Caribbean, it is evident that there was a massive increase in the population of these societies as a result of the importation of indentured labourers to replace slaves over the course of the nineteenth century. This also happened to coincide with the industrial intensification of plantation agriculture in the Caribbean, and according to Christian Schnakenbourg's figures this amounted to the importation of 487,000 East Indians, 262,000 Africans, 159,000 Chinese, and 32,000 Portuguese (1984: 92).

${ }^{16}$ See the 1911 Rockefeller Foundation Report for an approximation of these figures.
} 
to using the tunnels as latrines due to lack of adequate underground santiation; but what made the problem worse were the damp and muddy conditions that the miners worked in, and the fact that they often worked topless and traipsed mud around on their boots which rubbed off on to ladders and other surfaces their skin came into contact with. It is also likely that the degree of soil infestation in the mine combined with the damp conditions contributed to the severe cases of the "bunches" that the Dolcoath miners complained about, and in turn explains why hookworm larvae were able to penetrate the damp clothes of the workers (Boycott and Haldane 1904: 104). ${ }^{17}$

According to Boycott and Haldane there were no comparable outbreaks of hookworm disease in any other British mines at the time because these mines were not deep enough, or either too cool or too dry. But a study of hookworm infection rates among gold miners working in the deep mines of California by Cumming and White (1917) suggests that we need to take into account how other factors can increase exposure to infection. Their survey of the "Mother Lode" mines shows that infection levels varied from one mine to the next and depended on a number of factors. In addition to measuring how deep the mines were and their underground temperature, Cumming and White assessed how much water the mines produced, the sanitary condition and general state of cleanliness, and how many levels and miners worked underground. What their survey shows is that hookworm infection rates were highest in the gold mines that were warm and humid, produced more water and had a poor state of cleanliness, and had deeper shafts with more levels and miners working on them - thus serving to underline the relationship between hookworm infection and population density (cf. Cumming and White 1917: 20-21, 24-25, 33-34). Yet although soil pollution and poor sanitation were thought to be the principal causes of hookworm infection in the "Mother Lode" mines (cf. Nauss 1921), Cumming and White argue that water also helped to disseminate infective larvae and provided humid conditions that were ideal for their propagation. Upon comparing the tasks miners performed underground, the authors discovered that those miners working closest to the mine shafts (where much of the water drained) and had been working in the mine for longer periods of time, were more likely to be infected (Cumming and White 1917: 31-32).

It is instructive to compare the surveys of hookworm infection in European and North American mines with similar surveys undertaken in Australia and China at the beginning of the twentieth century (Reed 1914; Sawyer 1924). Spurred in part by these and similar studies that were initiated at the behest of the Rockefeller Foundation's efforts to eradicate hookworm disease throughout the world, the latter studies demonstrate in Australia and China the outbreak of hookworm infection in coal mines was also related to the industrial intensification of mining. Rates of hookworm infection rates in Australian and Chinese coal mines were also high and in some cases produced clinical signs of the disease, but not all of these mines had high rates of infection, and not all were infected. In a report based on research that came out of the Australian Hookworm Campaign, Sawyer (1924: 160-165) notes that only two coal mines in Australia had notable rates of hookworm infection, with only one of these mines producing what could be considered as clinical signs of hookworm disease amongst the workers. While in a more detailed study of a Chinese coal mine, Reed (1914: 147-153) determined that close to $100 \%$ of underground workers were infected and had high degrees of infection, which he ascribes to similar conditions described in Boycott and Haldane's surveys of Cornish tin miners (1903, 1904, 1909) and Cumming and White's survey of Californian gold miners (1917). Invariably, all of the surveys concluded that improvements had to be made to sanitation and a more effective latrine system introduced to reduce exposure to hookworm infection amongst underground miners.

A study of a Chinese coal mine furnishes us with clear evidence of the reduction in hookworm infection rates affected by improvements to underground sanitation. Yang et al.'s (1985) study shows that from 1950 to 1980, hookworm infection rates declined from 60\% to 20\%, which the authors ascribe to improvements in underground sanitation and the wearing of appropriate footwear. Yet it is of interest to note that over the same period, rates of respiratory disease amongst Chinese coal miners in Huainan had not substantialy decreased. I raise this because it serves to underline why it is problematic to refer to hookworm disease amongst miners as an "occupational disease" (Cort 1918; Sawyer 1924). As I see it, the main

\footnotetext{
${ }_{17}$ See Boycott and Haldane (1904: 88-89) for a glass plate depicting a truly horrific example of hookworm dermatitis suffered by a Dolcoath miner and perhaps also underlining just how severe levels of soil infestation could get in industrial mines.
} 
difference between the former and the latter is that in the case of the respiratory diseases miners suffer from, they are contracted from working with materials injurious to human health which are largely unavoidable, whereas in the case of hookworm infection it is primarily a result of inadequate underground sanitation in mines. While the latter can easily be remedied and is not strictly related to the type of materials miners work with, ${ }^{18}$ in the case of respiratory diseases the problem cannot easily be overcome and continues to be a major health problem in the mining industry (Ross and Murray 2004). By contrast, and not unlike the respiratory diseases miners suffer from, the role of human-manure-farming in the spread of hookworm disease also seems to be related to working with materials difficult to avoid and injurious to human health. Even though the health risks are now widely recognized in China, farmers continue to use human manure to fertilize crops because chemical alternatives are too expensive or due to impracticalities involved in destroying hookworm larvae when faeces is stored as night-soil.

\section{Plantation agriculture in India and the Caribbean}

Industrial mining and plantation agriculture were each instrumental in the spread of hookworm disease at the turn of the twentieth century because they required a large labor force that was compelled to work in confined areas, and not enough was done to meet their sanitary needs. But we should not forget that miners and plantation laborers were differentially exposed to sources of hookworm infection and that this depended not only on the type of work they did but also the ecology of their environment. With respect to the outbreaks of hookworm disease that were documented in the mines of Europe and North America, for example, normally hookworms cannot survive in cold climates but they were able to thrive in certain types of mines because deep mines in particular produced ideal ecospheres for their propagation. In these circumstances, only the underground miners were exposed to sources of hookworm infection because the temperature was too cold at the surface and not humid enough and sanitary conditions in the mines were primitive. With respect to plantation agriculture on the other hand, while laborers can be exposed to sources of hookworm infection when they work in the fields, parasitological studies suggest that the main sources of infection usually lies closer to where they reside (Chandler 1929: 193-196; cf. Cort 1925: 60-69). As I pointed out earlier, this is because they repeatedly visit the same areas to defecate out of a concern for both privacy and ease of access. ${ }^{19}$ Thus in the case of plantation agriculture in regions such as India and the Caribbean, we must pay attention not only to the workplace but also the residential settlement patterns of laborers and their families, as this is just as likely to determine the degree to which they are exposed to hookworm infection.

The first studies I shall refer to are the series of surveys William Cort and his collaborators produced on hookworm infection rates amongst plantation laborers in the Caribbean. The authors discovered high infection rates amongst laborers working on sugar and coffee plantations in both Trinidad and Puerto Rico, pointing out that laborers complained of ground itch when working in parts of the fields where other laborers had defecated and adult males and females averaged egg counts between 2,000-8,000 per gram (Cort and Payne 1922a; Cort et al. 1923a, 1923c, 1923d). What is particularly interesting about these surveys is that the authors also sought to assess the degree of soil infestation to better determine how hookworm infection was transmitted utilizing the Baermann isolation apparatus to calculate how many infective larvae could be found in the samples of human faeces they collected. Although the authors concluded that coffee plantations produced more ideal conditions than sugar plantations for the propagation of infective larvae as a result of the amount of shade retaining moisture made available by coffee plants, what their surveys also underline is that

\footnotetext{
${ }^{18}$ Here the same would apply to the claim that hookworm infection deriving from plantation work is as an occupational disease (Smillie 1922). For his part, Chandler (1929: 174-179, 184, 194) rejects this claim by underlining that the sources of hookworm infection plantation laborers are exposed to are not restricted to working in the fields, but also stem from using areas surrounding their barracks as defecation sites. Chandler $(1929$ : 180, 188) argues that only human-manurefarming can be regarded as an occupational disease, pointing out the principal source of infection stems from working in the fields and not soil pollution as farmers collect and use human manure rather than waste it. However, I think the distinctions I have made, that of working with materials injurious to human health and the extent to which they can or cannot be avoided, offer more parsimonious criteria for evaluation.

${ }^{19}$ Chandler (1929: 191) suggests similar considerations would have determined where miners chose to defecate and that repeatedly visiting the same defecation sites in underground tunnels that lacked appropriate sanitation is likely to have increased suspectibility to hookworm infection.
} 
the level of soil infestation was often worse closer to people's homes on the edge of sugar and coffee plantations where laborers and their families were more likely to defecate. As Cort (1925: 60-61, 69) points out in the conclusion to this series of surveys, the likelihood that laborers are exposed to sources of hookworm infection closer to where they reside rather than where they work was due in large part to ease of access and repeated visits to "protected" defecation sites. This finding was brought out in one survey illustrating that female adults suffered from higher infection rates than adult males living in the same village despite the fact that they did not work as regularly as the adult males as plantation laborers (Cort et al. 1923c).

Chandler's surveys of hookworm infection rates amongst tea plantation laborers in India agrees with most of Cort's findings for sugar and coffee plantation laborers in the Caribbean. However, what is important about Chandler's findings is his discovery that plantation laboring populations in the northeast provinces of India ${ }^{20}$ not only had the highest rates of hookworm infection in the subcontinent, ${ }^{21}$ but also that hookworm infection rates were worse among tea plantation laborers than in neighboring villages in the provinces of Assam and Bengal (1925, 1926b). According to Chandler, because these tea plantation laborers lived in more "compact" settlements and had fewer defecation sites to choose from ${ }^{22}$ and also sort a modicum of privacy when they defecated (cf. Chandler 1929: 193-196), ${ }^{23}$ this resulted in the concentration of soil pollution in the vicinity of their barracks and in parts of the fields where they worked leading to higher infection rates. For instance, Tukvar Tea Estate, which Chandler (1926b: 494-495) says was typical of tea plantations in the northern part of the Darjeeling district in Bengal, had a hookworm infection index of 429, while the nearby village of Kalimpong, which has a similar elevation and climate to Tukvar Tea Estate, had an infection index of 192. Upon breaking these figures down, Chandler indicates that the prevalence of infection was $90.5 \%$ and that laborers had an average egg count of 2,418 per gram, ${ }^{24}$ adding that the tea plantation's cultivation methods which increased the moisture content and helped loosen the soil produced ideal conditions for the propagation of hookworm larvae. Apparently laborers disliked plucking tea on account of the ground itch they contracted when working in the fields, with women more likely to suffer from higher egg count averages than men, because it was their job to pick leaves from the bushes where laborers often defecated as a result of the cover the bushes afforded (Chandler 1926b: 500-501).

Several consequences follow from these studies of outbreaks of hookworm disease amongst plantation laboring populations in India and the Caribbean at the turn of the twentieth century. Historians who have critically assessed the efforts of the Rockefeller Foundation to eradicate hookworm disease from British colonies with plantation sectors - though not the work of parasitologists such as Cort and Chandler, strangely enough - have accused colonial officials and plantation owners of failing to prevent the spread of the disease because they did not do enough to improve sanitary conditions (Hewa 1994; Pemberton 2003). However, as Cort and Chandler point out in their surveys of plantation laboring populations in India and the Caribbean, the provision of latrines could not guarantee their use, as they quickly fell into disuse if the latrines were not regularly cleaned (cf. Cort and Payne 1922a: 121; Chandler 1926b: 502-503). And as Cort and Chandler also underline, none of the laborers had used latrines before, suggesting it would take some time before they became familiar with their use (and we must bear in mind that footwear was not common in those days either). This brings me to another concern I have with the conclusions of historians such as Rita Pemberton and Soma Hewa, which is that in accusing colonial officials and planters of failing to prevent the spread of

\footnotetext{
${ }^{20}$ This labor force was largely made up of migrants from other parts of India, particularly tribal peoples of Central India who were willing to work for lower wages than local populations (Bhowmik 2002: 139-143).

${ }^{21}$ Chandler's (1927) findings for plantation laborers in South India are inconclusive, but in a review of his work Patel (1954) indicates that they also suffered from the highest rates of infection in their region.

${ }^{22}$ Chandler does not indicate how densely populated these settlements were. But he cites the example of a family who lived in more isolated surroundings and had more defecation sites to choose from and as a result had lower hookworm infection rates than their neighbours to illustrate the relation between population density and likelihood of exposure to infection in the tea plantations of Assam and Bengal (1929: 195-196).

${ }^{23}$ Chandler $(1925,1926 b)$ also points out that infection rates are compounded by the fact that in repeatededly visiting the same defecation sites, laborers may stand on old stools that are not visible to the human eye following degradation but could still contain infective larvae.

${ }^{24}$ According to Chandler (1926b: 495) hookworm infection rates on Tukvar and other Himalayan tea plantations "must have been considerably worse in times past", as a great deal had already been done to try to reduce the spread of the disease beginning in 1917 with the start of a hookworm campaign and mass treatments of plantation laborers.
} 
hookworm disease on agricultural estates in former British colonies in the Caribbean and Sri Lanka, they did not investigate what sanitary conditions were like in the villages. Not only were the conditions remarkably similarly (cf. Philips 1955; Couacaud 2011), but in view of the findings by Cort and Chandler, it is more than likely that people residing in the villages - whom constituted a significant proportion of the population in these societies - would have used the edges of the plantations as defecation sites which is where it has been suggested the risk of exposure to hookworm infection was often greatest ${ }^{25}$ and had an equally important part to play in the spread of the disease. ${ }^{26}$

These oversights concern a more fundamental issue. It is easy, and perhaps comforting with the benefit of hindsight, to blame the ruling elites for failing to prevent the outbreak of hookworm disease amongst colonial plantation laboring populations. But this fails to appreciate that while providing latrines would have gone some way towards reducing the incidence of hookworm disease, it was the sudden and rapid increase in the population of these predominantly agrarian societies and the absence of adequate sanitation that was the ultimate cause of the hookworm epidemics that broke out in former British colonies ${ }^{27}$ and other plantation societies in the Americas. ${ }^{28}$ This issue has not only escaped the attention of most historians, but also seems to have eluded parasitologists such as Cort (Cort and Payne 1922a, 1922b) and Chandler (1929), who have argued that soil pollution was the main cause of the spread of hookworm disease amongst plantation laboring populations. Although Chandler refers on a number of occasions in his work to the relationship between population density and outbreaks of hookworm disease (1926b, 1926c, 1929), he never developed this insight; most probably because he did not appreciate how radically the capitalist forms of development were transforming the working and living conditions of vast swathes of the world's population at the turn of the twentieth century (cf. Palmer 2009, 2010: 26-29). In the case of industrial mining, while this industry radically transformed the lives of Europe's rural population and the many who emigrated to North America and ending up working there as miners too, the relationship between population density and outbreaks of hookworm disease primarily affected underground miners and only became an issue in mines that were deep, and warm and moist enough, to allow the parasite to propagate. Whereas in the case of plantation agriculture, it would seem that the dense population that the parasite requires to proliferate, and in turn to constitute a public health problem, primarily affected former slave or immigrant populations that were housed on or settled in close priximity to agricultural estates in former British colonies and other plantation societies in the Americas.

It is interesting to compare Cort and Chandler's surveys of hookworm infection rates amongst plantation laboring populations in India and the Caribbean at the turn of the twentieth century with more recent surveys in these areas. In India, for example, there does not appear to have been a noticeable decrease in hookworm infection rates with surveys indicating that laboring populations in the tea plantation areas of Assam and Bangladesh are still at high risk of infection (Gilgen et al. 2001; Traub et al. 2004). In fact, Traub et al. state that they are sceptical of the benefits of administering anthelmintic drug treatments due to the likelihood of reinfection, pointing out that defecation outdoors remains common and many laborers prefer to

\footnotetext{
${ }^{25}$ Neither Cort nor Chandler conducted detailed surveys of defecations habits in the fields where the plantation laboring populations worked. But Cort (1941: 311) persuasively argues that risk of exposure to hookworm infection would be less great in the fields because of lack of sufficient faecal concentration comparable to that found in close proximity to where laborers resided and defecated more regularly.

${ }^{26}$ This is in fact what a series of sanitary reports commissioned by the British colonial authorities in the Indian Ocean island of Mauritius confirm (Balfour 1922). The expert commissioned to write the reports, Andrew Balfour, underlines the threat that sugarcane fields lying in close proximity to villages and urban conglomerations posed to public health because of the propensity of the local population to use these areas as defecation sites. The threat to public health Balfour was referring to was hookworm disease, which a representative of the Rockefeller Foundation had documented was of epidemic proportions in Mauritius after conducting an investigation in 1920.

${ }^{27}$ I am not trying to absolve colonial officials and plantation owners of their legal and moral responsibilities as custodians of their workforces (cf. Couacaud 2011). Rather, the point I am seeking to underline is that it is inappropriate to level the blame squarely on the shoulders of colonial officials and plantation owners as there were other factors involved in the spread of hookworm disease beyond their control.

${ }^{28}$ It is conditions similar to these that are said to have resulted in disease outbreaks in urban parts of Great Britain during the Industrial Revolution due to "a geographically more intensive demand for labour than had hitherto existed" and which subsequently led to calls for major reforms in public health engineering (Szreter 1988: 18-20).
} 
go barefoot. ${ }^{29}$ In the Caribbean on the other hand, there has been a noticeable improvement, with across the board decreases in hookworm infection rates for most countries surveyed, according to Tikasingh et al. (2011). With the exception of Belize, all the countries surveyed recorded notable decreases in infection rates that the authors put down to the hookworm control programs and sanitary reforms initiated by the Rockefeller Foundation at the beginning of the twentieth century. The authors also point to continuing efforts by commonwealth governments to institute public health reforms and improvements in the economic conditions of the region's population as reflected in "improved water supplies, modern privies, [and] wearing of shoes even by farmers were also partly responsible for the reductions of infection" (2011: 30). ${ }^{30}$ The contrasting fortunes of these laboring populations not only illustrates my earlier point that growing urban development offers a more reliable way of measuring the likelihood of the decreasing incidence of hookworm infection. Laborer fortunes also illustrate that the kind of changes required to combat hookworm disease take time, and no single measure will be effective by itself.

\section{Indigenous settlements in Australia}

The forced settlement of indigenous peoples in Australia and the subsequent outbreaks of hookworm infection that were documented amongst these populations at the turn of the twentieth century brings us to the final example of the relationship between hookworm disease and economic development. In contrast to industrial mining and plantation agriculture, however, the relationship between population density and hookworm disease is even more explicit in the case of indigenous Australians who were forced to (or in some cases voluntarily) settled on reserves and stations as no labor-intensive industries were directly involved in this process. In fact, the mere act of imposing restrictions on the movements of what had previously been a highly mobile hunter-gathering population and confining them to small, densely populated settlements while failing to meet the sanitary needs of such a compact population was usually enough to expose indigenous Australians living in these settlements to high risk of infection from hookworm disease. Nevertheless, it is evident that these developments were the indirect result of economic initiatives undertaken by Australian governments to requisition land for the benefit of sheep and cattle farmers and capitalist industries and had the effect of transforming a formerly nomadic peoples into a sedentary population over a relatively short period of time. As I will show, there are striking parallels between the living conditions characterizing indigenous settlements in Australia at the turn of the twentieth century and the conditions one is likely to find in refugee camps in developing countries today, alerting us to the potential risk from hookworm infection that these populations can be exposed to at times of crisis especially in tropical or subtropical parts of the world where footwear and access to piped water and sanitation remain uncommon.

Like so many other parts of the world during this era, a hookworm control campaign was launched in Australia in the 1920s with the support of the Rockefeller Foundation. Based on a comparison of racial categories in use at the time, the report concluded that indigenous peoples confined to settlements suffered from the highest rates of hookworm infection, followed by Pacific Islanders and southern European immigrants living in plantation areas, with the lowest rates of infection amongst the white Australian population. However, earlier surveys carried out in Irian Jaya and Papua New Guinea determined that plantation workers suffered from higher rates of infection than village populations, and that white miners in some Queensland shires suffered from comparable rates of infection to indigenous peoples living in settlements in Australia, thus undermining attempts to establish a link between suspectibility to hookworm infection and race. But that did not prevent the authors of the report from viewing indigenous Australians and southern European immigrants as reservoirs of infection and sources of danger to the "white [Australian] race", ultimately reducing the problem to their "lax sanitary habits" rather than adequately investigating the extent to which provisions had been made for the sanitary needs of these populations (Sweet 1924: 8, 36). The report also indicates that no sources of hookworm infection were found in the cooler southern states of

\footnotetext{
${ }^{29}$ Traub et al. (2004: 696-699) point out that despite the fact that $80.2 \%$ of the surveyed population had access to functional indoor toilets only $65.2 \%$ used them. The authors suggest this was due to a range of factors including a reluctance to shed traditional defecation habits, malfunctioning septic tanks, and lack of access to running water (cf. Bhowmik 2002: 152-156).

${ }^{30}$ The situation in the Indian Ocean island of Mauritius shares many similarities with those described in the Caribbean (cf. Mohith et al. 2011; Couacaud 2011).
} 
Victoria, South Australia and Tasmania, and that for the warmer states and territories of New South Wales, Western Australia, Queensland and the Northern Territory, infection rates were consistently highest amongst indigenous populations confined to reserves and stations. ${ }^{31}$ Although the report does allude to clinical signs of the disease amongst the indigenous population (Sweet 1924: 36), it does not provide us with reliable estimates of the severity of infection because egg counting methods were not used and they only sought to calculate the percentage or incidence of infection.

It is also difficult to get a sense of what conditions were like on these settlements as the Australian Hookworm Campaign focused for the most part on assessing the state of sanitation amongst the majority white population. However, a more detailed survey of indigenous settlements in the Cape York Peninsula was conducted between 1920-1922 as part of the Campaign and underlines that no provisions had been made for the sanitary needs of these populations. Upon comparing conditions in these setttlements, the authors of the report point out that stations "showed no sanitary arrangements of any sort", while the reserves barely fared much better, having at most one earth closet and no provisions for their indigenous populations (Murray and Metcalfe 1922: 11). Apparently the hookworm infection rate amongst indigenous populations living on the reserves was $60.8 \%$, while the stations had an infection rate of $81 \%$; according to the authors of the report, in one of the missions they surveyed cases of "grass-itch" were documented which they suggested "resembles the "ground-itch" of hookworm disease" (Murray and Metcalfe 1922: 4). Further information on what conditions were like in indigenous settlements that were exposed to hookworm infection at the turn of the twentieth century can be gleaned from Settlement: a history of Australian Indigenous housing (Read 2000). Drawing upon government reports as well as the oral testimony of indigenous peoples who grew up on these settlements, several of the contributors to Settlement highlight that indigenous settlements located in Australia's warmer states and territories at this point in time were characterized by sub-standard housing, over-crowded living conditions, and lack of access to adequate sanitation (Briscoe 2000; Rowse 2000; Wells 2000).

While there has been a general improvement in indigenous housing in Australia, studies show that living conditions still leave much to be desired in remote settlements (Long 2000; Pholeros et al. 2000). It should not surprise us to learn, therefore, that a relatively recent review of the literature on hookworm infection in Australia found it continues to affect only indigenous communities (Provic and Luke 1995). However, perhaps what is surprising is that even though it is now common knowledge that over-crowding and poor sanitation plagued indigenous settlements in Australia for much of the twentieth century (Booth and Carroll 2005; Long et al. 2007), parasitologists and social scientists who have researched these communities and seem to be aware of the relationship between population density and suspectibility to hookworm infection continue to talk past each other. For instance, as the editor of Settlement points out it was the "gathering together large numbers of people culturally accustomed to living in small groups" that was the cause of the outbreak of hookworm disease in indigenous settlements at the turn of the twentieth century (Read 2000: 38). Similarly, in their recent review of the literature on hookworm infection in Australia, Provic and Luke (1995: 154) suggest that: "The more recent confinement of Aboriginals in crowded, insanitary reserves stimulated the proliferation of endemic parasites, including perhaps hookworms". Yet if we compare more recent parasitological surveys of a remote indigenous settlement in north Western Australia (Hopkins et al. 1997; Reynoldson 1997, 1998), it would appear the researchers remain unaware of the relationship between population density and suspectibility to hookworm infection. This is in spite of the fact that Reynoldson et al. (1998: 35) established a positive correlation between household size and the intensity of hookworm infection in their study - though without indicating if was a product of over-crowding or describing what sanitary conditions were like in this indigenous community. ${ }^{32}$

\footnotetext{
31 The Australian Hookworm Campaign report does not say anything about rates of hookworm infection amongst the non-settled indigenous population in Australia. But Provic and Luke (1995:152) cite one study conducted in 1928 in the Northern Territory indicating that the disease was "rare among Aborigines who did not come in contact with whites".

${ }^{32}$ For other studies that have established a positive correlation between household size and increased suspectibility to hookworm infection see Chongsuvivatwong et al. (1996), Olsen et al. (2001), Traub et al. (2004), Saathoff et al. (2005), and Pullan et al. (2010). For a study that problematizes and did not establish a positive correlation between population density and suspectibility to hookworm infection, see Koroma et al. (2010).
} 


\section{Refugee camps}

These findings have important ramifications for the study of infectious diseases in refugee camps. Faced with the sudden and rapid increase in numbers that refugee camps have to contend with as a result of man-made or natural disasters, it often proves difficult for aid workers to meet the sanitary needs of these large populations, and as has so often proven to be the case in the past, it does not take long before infectious diseases spread amongst these displaced populations (Toole and Waldman 1988). This lesson appears to have been learned, and most not-for-profit public health organizations now circulate manuals explaining to aid workers how to prevent disease outbreaks in refugee camps by installing waste disposal systems and ensuring access to public latrines. But the connection between the increased likelihood of exposure to hookworm infection and the conditions one typically finds in refugee camps appears to be less well recognized, with relatively little research being done in this area, according to Beyrer et al. (2011: 5). Beyrer et al. further underline that displaced persons make ideal targets for intestinal parasites in view of the perfect environment created for transmission by the crowded and unsanitary conditions that refugee camps tend to promote, and warn of increased susceptibility to infection among what are often malnourished populations.

It is also important to note that in contrast to the history of indigenous settlements, refugee camps are normally envisioned as temporary solutions and hence the possibility of being exposed to severe cases of hookworm "infestation" is not as great as in indigenous settlements where the population is likely to consist of more heavily infested individuals. ${ }^{33}$ Yet as so often happens in conflict situations, it often becomes difficult to repatriate refugees to their original homelands, and thus in those situations where displaced persons are forced to settle indefinitely in refugee camps, exposure to hookworm infection and transmission between heavily and lightly infested individuals are likely to increase.

\section{Discussion and conclusion}

The main hypothesis I put forward for consideration in this article is that the outbreaks of hookworm disease that were documented in different parts of the world at the turn of the twentieth century were a result of changes promoted by capitalist development. In order to establish the criteria for evaluating this claim, I made a point of distinguishing the former outbreaks from the human-manure-farming induced cases of hookworm disease documented in China in the first half of the twentieth century. Although the evidence seems less convincing when it comes to the postulated relationship between sweet potato cultivation and the spread of hookworm disease, in the case of seri-culture it does appear to be the case that it, and the use of human manure as a fertilizer, is a centuries-old tradition. As such, the postulated relationship between human-manure-farming and the spread of hookworm disease in China is not likely to be as recent as the outbreaks documented in other parts of the world at the turn of the twentieth century and which were associated with the expansion of labor-intensive capitalist forms of development. Also, the fact that transmission of infection is primarily affected through the use of human manure as a fertilizer, rather than risk of exposure to infection as a result of soil pollution and inadequate sanitary conditions (as was the case in industrial mining and plantation agriculture), points to the importance of the relationship between population density and outbreaks of hookworm disease. As a number of earlier parasitological studies underline (Cort et al. 1926; Chandler 1929; Chang et al. 1949), in the case of human-manure-farming, transmission of infection is not the result of soil pollution, but primarily stems from the collection and use of human manure as a fertilizer; while evolutionary anthropologists underline that problems with disposal of human waste as a result of the transition from a mobile hunter-gathering to a sedentary agricultural and industrial lifestyle have had important consequences for the spread of infectious diseases among densely populated human settlements.

However, that does not mean that any form of capitalist development will promote the spread of hookworm disease, and we should also be careful not to make the mistake of assuming that a strict

\footnotetext{
33 According to Chandler (1929: 232-233), the term infestation refers to the fact that unlike bacterial and protozoal infections, hookworms do not multiply in the body of the host but rather the rate of acquisition of worms depends on contact with polluted soil. Hence the more heavily polluted the soil is, the greater the chance of the presence of infective larvae, and the more likely an individual will be infected with hookworms, especially if they repeatedly visit the same defecation sites.
} 
correlation can be made between population density and outbreaks of the disease. As Chandler (1929) points out, not all types of plantation agriculture provide favorable conditions for the propagation of infective larvae, with variables such as climate, soil and moisture all playing important roles; ${ }^{34}$ in addition, we must pay attention to the specific type of working conditions or settlement patterns promoted by the relevant industry to determine its possible relationship to the spread of hookworm disease. For instance, mobile working populations employed in the construction of railroads or slaves employed in clearing forests for plantations on the frontiers of capitalist development (Palmer 2009: 678-679), are less likely to be exposed to risk of infection from hookworm larvae than sedentary working populations for the reasons set out in Chandler and Cort's surveys (Chandler 1925, 1926b, 1929; Cort and Payne 1922a; Cort et al. 1923a, 1923c, 1923d; Cort 1925). ${ }^{35}$ Their surveys demonstrate that repeatedly visiting the same defecation site increases the likelihood of exposure to hookworm infection, as it is in these areas that one is more likely to find a greater degree of soil pollution and soil infestation. This, in turn, explains why industrial miners in Britain and North America, and plantation laborers in India and the Caribbean, were so susceptible to infection from hookworm larvae as they worked or had settled in a given locality for an extended period of time where they also happened to defecate. And this is also the reason why to begin with displaced populations in refugee camps will be at less risk, but over time could become just as vulnerable as the indigenous populations who were forcibly settled onto reserves and stations in Australia at the turn of the twentieth century demonstrate.

Thus in view of the fact that hookworm disease is unlikely to proliferate unless there is a sufficiently large or densely concentrated population to facilitate its transmission, it is also unlikely that human history has witnessed hookworm epidemics on a comparable scale to those that were documented at the turn of the twentieth century. Nor are we likely to witness outbreaks of the same order of magnitude in the future, due in part to advances in preventive medical intervention and because the mass labor migration involved with the expansion of industrial mining and plantation agriculture on rural frontiers in the nineteenth and early twentieth century is unlikely to be repeated on a similar scale again. A possible exception to what I am proposing might be provided by irrigation agriculture, which has not only been shown to be related to the spread of hookworm infection (Chandler 1929; Pawlowski et al. 1991; cf. Palmer 2010: 28), but also has an ancient pedigree in a number of civilizations and could have caused epidemics of a comparable scale to those associated with industrial mining and plantation agriculture. And in fact, one study by an archaeoparasitologist (Keita 2003) claims to have found tentative evidence of hookworm disease in ancient Egypt at a point in time when irrigation agriculture (or basin irrigation) was already flourishing. However, detailed parasitological surveys by James Scott (1937a, 1937b) appear to problematize the possibility that this would have been the result of an epidemic, as the surveys he conducted in the 1930s demonstrate that in the case of Egypt, irrigation agriculture (be it basin or perennial) was not responsible for producing high infection rates or a hookworm epidemic. According to Scott, this is due to the fact that in the Egyptian villages he surveyed, the inhabitants rarely defecated in the fields, and the soil where they did regularly defecate closer to the villages was too compact and dry for the successful propagation of hookworm larvae. ${ }^{36}$

The other hypothesis I put forward for consideration in this article is the claim that the decreasing incidence of hookworm infection can serve as a useful measure of urban development. In contrast to Hotez (2002), I suggested that it is not "economic development" per se that has been responsible for the eradication

\footnotetext{
${ }^{34}$ For more recent parasitological studies that have documented outbreaks of hookworm disease among banana plantation labourers in Zimbabwe and rubber plantation labourers in Indonesia, see Chandiwana (1991) and Basta et al. (1979) respectively.

${ }^{35}$ Steven Palmer is one of the few historians to have recognized the relationship between population density and the outbreaks of hookworm disease that were being documented in different parts of the world at the turn of the twentieth century. Palmer also connects these developments to the expansion of capitalist forms of development and the requisite demand of these industries for cheap and plentiful supplies of labor. What is problematic about Palmer's reasoning, however, is his claim that these developments were primarily a result of the ecological transformations wrought by capitalist forms of development and his failure to consult contemperanous parasitological studies carried out in these localities. This is reflected in his somewhat naive claim that Caribbean plantation laborers were "defecating "ad lib" in the moist soils of the sugar, rice, and cocoa plantations in the course of their work" (Palmer 2009:703). As Cort et al.'s surveys illustrate, plantation laborers and their families did not defecate wherever they saw fit as the term ad lib implies, but chose specific places and usually for the privacy these places afforded, and indeed it is also for this reason that they were more likely to be exposed to sources of hookworm infection.

${ }^{36}$ This assumes that ecological conditions (and the defecation habits of the people) have not changed considerably in Egypt and the Nile valley since ancient times but may warrant further investigation.
} 
of hookworm disease from a number of industrialized societies, but urban development in particular. One could for instance seek to determine if a correlation can be established between the decreasing incidence of hookworm infection and economic growth as Hotez has done for China; however, I imagine that the decreasing incidence of hookworm infection can more accurately be gauged by noting the presence or absence of a number of key urban indices as I sought to demonstrate in this article. Determining if shoes are regularly worn, if homes have wooden or concrete flooring as opposed to earthen floors, and if toilets are connected to waste disposal systems, ${ }^{37}$ not only provides a more reliable way of ascertaining if hookworm infection rates are likely to decline but also of gauging the level of urban development that has taken place in a given locality. The merit of this approach was clearly brought out when I compared the fortunes of plantation laboring populations in India and the Caribbean and showed that hookworm infection rates have declined in most Caribbean countries since the turn of the twentieth century. The same cannot be said for tea plantation laborers in northeast India, where infection rates have not noticeably decreased and many laborers do not regularly wear shoes or have access to piped water and latrines connected to waste disposal systems. Similarly, it was noted that one of the reasons why hookworm infection rates have not appreciably declined in some remote indigenous communities in Australia is because these settlements remain undeveloped and lack the basic kind of services and urban amenities that most other Australians have access to.

\section{References}

Anderson, W. 1995. Excremental colonialism: public health and the poetics of pollution. Critical Inquiry 21(3): 640-669. .1998. Disease, culture and history. Health and History 1(1): 30-34.

Balfour, A. 1922. Report on Medical and Sanitary Matters in Mauritius. London: Waterlow and Sons Ltd.

Basta, S.S., Soekirman, D. Karyadi and N.S. Scrimshaw. 1979. Iron deficiency anemia and the productivity of adult males in Indonesia. American Journal of Clinical Nutrition 32: 916-925.

Beyrer et al. 2011. Neglected tropical diseases, conflict, and the right to health. Washington D.C.: National Academic Press.

Boycott, A.E. and J.S. Haldane. 1903. An outbreak of Ankylostomiasis in England, No. 1. Journal of Hygiene 3(1): 95-1136.

.1904. "Ankylostomiasis"., No. II. The Journal of Hygiene 4(1): 73-111. 1909. The progress of Ankylostomiasis in Cornwall. The Journal of Hygiene 9(3): 264-270.

Bhowmik, S.K. 2002. Productivity and labor standards in tea plantation sector in India. In A. Sivananthiran and C.S. Venkata Ratnam (eds.) Labor and social issues in plantations in South Asia. New Delhi: International Labor Organization. Pp 133-136.

Booth, A. and N. Carroll. 2005. Overcrowding and indigenous health in Australia. Discussion Paper No. 498. Center for Economic Policy Research: Australian National University.

Bradley, M., S.K. Chandiwana and D.A.P. Bundy. 1993. The epidemiology and control of hookworm infection in the Burma Valley area of Zimbabwe. Transactions of the Royal Society of Tropical Medicine and Hygiene 87: 145-147.

Briscoe, G. 2000. Aboriginal shelters and the National Hookworm Campaign, Queensland, 1909-24. In P. Read (ed.) Settlement: a history of Australian indigenous housing. Canberra: Aboriginal Studies Press. Pp 75-84.

Brooker, S., J. Bethony and P.J. Hotez. 2004. Human hookworm infection in the 21st century. Advances in Parasitology 58: 197-288.

\footnotetext{
37 Some studies have established a positive correlation between hookworm infection and homes with earthen floors (Desowtiz et al. 1961; cf. Hotez 2008). Other studies suggest that hardened earth or mud floors are unlikely to enable hookworm larvae to successfully propagate because the soil is not loose or moist enough (cf. Cort and Payne 1922a:130132; Chang et al. 1949:119-120; Scott 1937b:515-516). However for our purposes, the more important issue is the likelihood that concrete and wooden homes will have toilets connected to waste disposal systems that should ensure an overall reduction in hookworm infection rates.
} 
Brooker, S., N. Alexander, S. Geiger, R.A. Moyeed, J. Stander, F. Fleming, P.J. Hotez, R. Correa-Oliviera and J. Bethony. 2006. Contrasting patterns in the small-scale heterogeneity of human helminth infections in urban and rural environments in Brazil. International Journal for Parasitology 36: 11431151.

Carroll, S.M. and J.C. Walker. Hookworm infection in Latin America and the Caribbean. In G.A. Schad and K.S. Warren (eds.) Hookworm disease: current status and new directions. New York: Taylor and Francis. Pp 33-43.

Chandiwana, S.K. 1991. Hookworm population ecology in Zimbabwe. In G.A. Schad and K.S. Warren (eds.) Hookworm disease: current status and new directions. New York: Taylor and Francis. Pp 165-176.

Chandler, A.S. 1925. The epidemiology of hookworm and other helminth infections on Assam tea estates. Indian Journal of Medical Research 13: 407-426.

.1926a. The prevalence and epidemiology of hookworm and other helminth infections in India. Part I: introduction and methods. Indian Journal of Medical Research 14: 185-194.

.1926b. The prevalence and epidemiology of hookworm and other helminth infections in India. Part V: tea estates of Assam and Bengal. Indian Journal of Medical Research 14: 493-504.

.1927. The prevalence and epidemiology of hookworm and other helminth infections in India. Part XI: Madras Presidency and southern states. Indian Journal of Medical Research 15: 159-179.

.1929. Hookworm disease: its distribution, biology, epidemiology, pathology, diagnosis, treatment and control. New York: The Macmillan Company.

Chang, K., W.K. Tong, H.T. Ch'in and C.H. Li. 1949. Studies on hookworm disease in Szechwan Province, West China. The American Journal of Hygiene, Monographic Series, No. 19. Baltimore: The John Hopkins Press.

Changhua, L., Z. Xiarong, Q. Dongchuan, X. Shuhua, P.J. Hotez, Z. Defu, Z. Hulian, L. Mingden, R. Hainan, Z. Bing, X. Haichou, J. Hawdon, and F. Zheng. 1999. Epidemiology of human hookworm infections among adult villagers in Hejiang and Santai counties, Sichuan Province, China. Acta Tropica 73: 243249.

Chongsuvivatwong, V., S. Pas-Ong, D. McNeil, A. Geater, and M. Duerawee. 1996. Predictors for the risk of hookworm infection: experience from endemic villages in southern Thailand. Transactions of the Royal Society of Tropical Medicine and Hygiene 90: 630-633.

Cort, W.W. 1918. Report of the division of parasitology. In Twenty-fifth biennial report of the State Board of Health of California, 1916-1918. Sacramento: California State Printing Office. Pp 78-81.

.1925. Investigations on the control of hookworm disease XXXIV: general summary of results. American Journal of Epidemiology 5(1): 49-89.

.1941. Epidemiology and sanitary measures for the control of nemic parasites of man. In J.R. Christie (ed.) An introduction to nematology. Baltimore: Monumental Printing Company. Pp 309-313.

Cort, W.W. and G.C. Payne. 1922a. Investigations on the control of hookworm disease VI: a study of the effect of hookworm control measures on soil pollution and infestation in a sugar estate. American Journal of Epidemiology 2(2): 107-148.

.1922b. Investigations on the control of hookworm disease VII: an epidemiological study of hookworm disease in a cacao estate. American Journal of Epidemiology 2(2): 149-161.

Cort, W.W., W.A. Riley, G.C. Payne, and R.B. Hill. 1923a. Investigations on the control of hookworm disease XXVI: an epidemiological study of a small village on the north coastal plain of Porto Rico. American Journal of Epidemiology 3(supp2): 61-72.

Cort, W.W., W.A. Riley, and G.C. Payne.1923b. Investigations on the control of hookworm disease XXVII: the study of an area in the mountains of Porto Rico, which had been influenced for twenty years by hookworm control measures. American Journal of Epidemiology 3(supp2): 73-84.

-1923c. Investigations on the control of hookworm disease XXVIII: a study of a heavily infested group of people on a sugar and coffee estate in Porto Rico, before and after treatment. American Journal of Epidemiology 3(supp2): 85-110. 
.1923d. Investigations on the control of hookworm disease XXIX: a study of the realtion of coffee cultivation to the spread of hookworm disease. American Journal of Epidemiology 3(supp2): 111-127.

Cort, W.W. J.B. Grant and N.R. Stoll. 1926. Researches on hookworm in China: embodying the results of the work of the China Hookworm Commission, 1923-1924. The American Journal of Hygiene, Monographic Series, No. 7. Lancaster: Lancaster Press Inc.

Couacaud, L. 2011. Working and living conditions of Mauritian sugar estate workers after indenture. In Truth and Justice Commission Report, Vol. 3, 338-365. Port Louis: Mauritius.

Cumming, J.G. and J.H. White. 1917. Control of hookworm infection at the deep gold mines of the Mother Lode, California. Bulletin 139. Washington: Government Printing Office.

Desowitz, R.S., V. Zaman and W.K. Ng. 1961. The incidence of intestinal parasites in various communities of Singapore Island. Singapore Medical Journal 2(3): 91-93.

Esrey, S.A., J.B. Potash, L. Roberts and C. Schiff. 1991. Effects of improved water supply and sanitation on ascariasis, diarrhoea, dracunculiasis, hookworm infection, schistosomiasis, and trachoma. Bulletin of the World Health Organization 69(5): 609-621.

Fenghua, S., W. Zhongxing, Q. Yixing, C. Hangqun, X. Haichou, R. Hainan, X. Shuhua, Z. Bin, J.M. Hawdon, F. Zheng and P.J. Hotez. 1998. Epidemiology of human intestinal nematode infections in Wujian and Pizhou counties, Jiangsu Province, China. Southeast Asian Journal of Tropical Medicine and Public Health 29(3): 605-610.

Gilgen, D., C.G.N. Mascie-Taylor, and L. Rosetta. 2001. Intestinal helminth infections, anemia and labor productivity of female tea pluckers in Bangladesh. Tropical Medicine and International Health 6(6): 449-457.

Gonçalves, M.L.C., A. Araujo and L.F. Ferreira. 2003. Human intestinal parasites in the past: new findings and a review. Mem. Inst. Oswaldo Cruz 98: 103-118.

Green, M.S., T. Swartz, E. Mayshar, B. Lev, A. Leventhal, P.E. Slater and J. Shemer. 2002. When is an epidemic an epidemic? Israel Medical Association Journal 4(1): 3-6.

Hawdon, J.M. and S.A. Johnston. 1996. Hookworms in the Americas: an alternative to trans-Pacific contact. Parasitology Today 12(2): 72-74.

Hewa, S. 1994. The hookworm epidemic on the plantations in colonial Sri Lanka. Medical History 38: 73-90.

Hobsbawm, E. 1968. Industry and empire: from 1750 to the present day. London: Penguin Books.

Hopkins, R.M., M.S. Gracey, R.P. Hobbs, R.M. Spargo, M. Yates and R.C.A. Thompson. 1997. The prevalence of hookworm infection, iron deficiency and anemia in an aboriginal community in northwest Australia. Medical Journal of Australia 166: 241-244.

Hotez, P.J. 2002. China's hookworms. China Quarterly 172: 1029-1041.

-2008. Hookworm and poverty. Annals of the New York Academy of Sciences 1136: 38-44.

Hughes, C.C. and J.M. Hunter. 1970. Disease and "development" in Africa. Social Science and Medicine 3: 443-493.

Inhorn, M.C. and P.J. Brown. 1990. The anthropology of infectious diseases. Annual Review of Anthropology 19: 89-117.

Keita, S.O.Y. 2003. A study of vault porosities in early Upper Egypt from the Badarian through Dynasty I. World Archaeology 35(2): 210-222.

King, F.H. 1911. Farmers of forty centuries: or, permanent agriculture in China, Korea and Japan. Madison, WI.: Self-published. Numerous reprintings and freely available.

Koroma, J.B., J. Peterson, A.A. Gbakima, F.E. Nylander, F. Sahr, R.J. Soares Magalhaes, Y. Zhang and M.H. Hodges. 2010. Geographical distribution of intestinal schistosomiasis and soil-transmitted helminthiasis and preventive chemopherapy strategies in Sierra Leone. PLoS Negl Trop Dis 4(11): 19.

Long, J. 2000. The Commonwealth Government and aboriginal housing, 1968-81. In P. Read (ed.) Settlement: a history of Australian indigenous housing. Canberra: Aboriginal Studies Press. Pp 103117. 
Long, S., P. Memmott and T. Sellig. 2007. An audit and review of Australian indigenous housing research, Final Report No. 102. Queensland Research Center: Australian Housing and Urban Research Institute.

Long-Qi, X., Y. Sen-Hai, J. Ze-Xiao, Y. Jia-Lun, L. Chang-Qui, Z. Xiang-Jun and Z. Chang-Qian.. 1995. Soil-transmitted helminthiases: nationwide survey in China. Bulletin of the World Health Organization 73(4): 507-513.

Marks, S. 1997. What is colonial about colonial medicine? And what has happened to imperialism and health? Society for the Social History of Medicine 10 (2): 205-219.

May, J.M. 1958. The ecology of human disease. New York: MD Publications.

Mayer, J.D. 1996. The political ecology of disease as one new focus for medical geography. Progress in Human Geography 20: 441-456.

McKweon, T. 1976. The modern rise in population. London: Edward Arnold.

Mitchell, B.R. 1984. Economic development of the British coal industry, 1800-1914. Cambridge: Cambridge University Press.

Mintz, S.W. 1956. Canamelar: the subculture of a rural sugar plantation proletariat. In J. Steward (ed.) The people of Puerto Rico: a study in social anthropology. Urbana, IL.: University of Illinois Press. Pp 314-417.

Mohith, J., T.K. Gunness, A.G. Dustagheer, V. Rajcoomar, N. Gopauloo and A. Soreefan. 2011. The health of slaves, indentured and their descendants. In Truth and Justice Commission Report, Vol. 3, 795-924. Port Louis: Mauritius.

Murray, G.A. and A.J. Metcalfe. 1922. The incidence of hookworm disease in the Thursday Island District of Northern Queensland. Brisbane: The Hookworm Campaign.

Naquira, C. 1990. Hookworm infection in Latin America and the Caribbean. In G.A. Schad and K.S. Warren (eds.) Hookworm disease: current status and new directions. New York: Taylor and Francis. Pp 5570.

Nauss, R.W. 1921. Hookworm in California gold mines. American Journal of Public Health 11(5): $439-451$.

Ngonjo, T.W., J.H. Kihara, M. Gicheru, P. Wanzala, S.M. Njenga and C.S. Mwandawiro. 2012. Prevalence and intensity of intestinal parasites in school age children in Thika District, Kenya. African Journal of Health Sciences 21: 153-160.

Olsen, A., H. Samuelsen and W. Onyango-Ouma. 2001. A study of the risk factors for intestinal helminth infections using epidemiological and anthropological approaches. Journal of Biosocial Science 33: 569-584.

Palmer, S. 2009. Migrant clinics and hookworm science: peripheral origins of International Health, 18401920. Bulletin of the History of Medicine 83: 676-709.

-2010. Launching global health: the Caribbean odyssey of the Rockefeller Foundation. Ann Arbor: The University of Michigan Press.

Patel, J.C. 1954. Ankylostomiasis in India: a review with suggestions for future research. Indian Journal of Medical Research 42(2): 279-304.

Patterson, J.T. 1998. How do we write the history of disease? Health and History 1(1): 5-29.

Pawlowski, Z.S., G.A. Schad and G.J. Stott. 1991. Hookworm infection and anemia: approaches to prevention and control. Geneva: World Health Organization.

Pemberton, R. 2003. A different intervention: the International Health Commission/Board, health, sanitation in the British Caribbean, 1914-1930. Caribbean Quarterly 49(4): 87-103.

Philips, J. 1955. The hookworm campaign in Ceylon. In Teaf H.M. and P.G. Franck (eds.) Hands across frontiers: case studies in technical cooperation. Ithaca, NY: Cornell University Press. Pp 265-305.

Pholeros, P., P. Torzillo and S. Rainow. 2000. Housing for health: principles and projects, South Australia, Northern Territory and Queensland, 1985-97. In P. Read (ed.) Settlement: a history of Australian indigenous housing. Canberra: Aboriginal Studies Press. Pp 199-208. 
Provic, P. and R.A. Russell. 1995. The changing epidemiology of human hookworm infection in Australia. Medical Journal of Australia 162: 150-154.

Pullan, R.L., N.B. Kabatereine, R.J. Quinnell and S. Brooker. 2010. Spatial and genetic epidemiology of hookworm in a rural community in Uganda. PLoS Negl Trop Dis 4(6): 1-10.

Read, P. 2000. Settlement: a history of Australian indigenous housing. Canberra: Aboriginal Studies Press.

Reed, A.C. 1914. Investigation of hookworm infection at the Ping Hsiang Colliery, Central China. American Journal of Public Health 4(12): 1136-1158.

Reynoldson, J.A., J.M. Behnke, L.J. Pallant, M.G. Macnish, F. Gilbert, S, Giles, R.J. Spargo and R.C.A. Thompson. 1997. Failure of pyrantel in treatment of human hookworm infections (Ancylostoma duodenale) in the Kimberley region of North West Australia. Acta Tropica 68: 301-312.

Reynoldson, J.A., J.M. Behnke, M. Gracey, R.J. Horton, R. Spargo, R.M. Hopkins, C.C. Constantine, F. Gilbert, C. Stead, R.P. Hobbs and R.C.A. Thompson. 1998. Efficacy of albendazole against Giardia and hookworm in a remote aboriginal community in the north of Western Australia. Acta Tropica 71:27-44.

Rose, W. 1911. The Rockefeller Sanitary Commission for the eradicaiton of hookworm disease: hookworm infection in foreign countries. Washington, D.C.: Offices of the Commission.

Ross, M.H. and J. Murray. 2004. Occupational respiratory disease in mining. Occupational Medicine 54: 304-310.

Rowse, T. 2000. Housing and colonial patronage, Alice Springs, 1920-65. In P. Read (ed.) Settlement: a history of Australian indigenous housing. Canberra: Aboriginal Studies Press. Pp 85-98.

Saathoff, E., A. Olsen, B. Sharp, J.D. Kvalsvig, C.C. Appleton and I. Kleinschmidt. 2005. Ecological covariates of hookworm infection and reinfection in rural KwaZulu-Natal/South Africa: a geographic information system-based study. American Journal of Tropical Medicine and Hygiene 72(4): 384391.

Sawyer, W.A. 1924. Hookworm disease as related to industry in Australia. American Journal of Tropical Medicine 3(3): 159-176.

Schnakenbourg, C. 1984. From sugar estate to central factory: the industrial revolution in the Caribbean (1840-1905). In B. Albert and A. Graves (eds.) Crisis and change in the international sugar economy, 1860-1914. Norwich and Edinburgh: ICS Press. Pp 83-93.

Scott, J.A. 1937a. The prevalence and distribution of hookworm infection in Egypt. American Journal of Epidemiology 26(3): 455-505.

.1937b. Observations on the transmission of hookworm infection in Egypt. American Journal of Epidemiology 26(3): 506-526.

Sen-Hai, Y. and S. Wei-Xia. 1990. Hoowkorm infection and disease in China. In G.A. Schad and K.S. Warren (eds.) Hookworm disease: current status and new directions. New York: Taylor and Francis. Pp 44-54.

Smillie, W.G. 1922. Studies on the hookworm infection in Brazil, second paper, 1918-1920. New York: The Rockefeller Institute for Medical Research.

Sorensen, E., M. Ismail, D.K.C. Amarasinghe, I. Hettiarachchi and T.S. Dassenaieke. 1994. The effect of the availability of latrines on soil-transmitted nematode infections in the plantation sector in Sri Lanka. American Journal of Tropical Medicine and Hygiene 51(1): 36-39.

Sweet, W.C. 1924. Final report of the Australian Hookworm Campaign. Brisbane: Australian Hookworm Campaign.

Szreter, S. 1988. The importance of social intervention in Britain's mortality decline c. 1850-1914: a reinterpretation of the role of public health. Society for the Social History of Medicine 1: 1-37.

Tang, C.C. 1949. Sweet-potato cultivation and hookworm disease in Fukien, South China. American Journal of Epidemiology 50(2): 236-262.

Thiessen, K. 2006. China chapter. In The Sweetpotato Atlas. CGIAR. Downloaded from: https://research.cip.cgiar.org/confluence/display/WSA/China. 
Tikasingh, E.S., D.D. Chadee and S.C. Rawlins. 2011. The control of hookworm disease in Commonwealth Caribbean countries. Acta Tropica 120: 24-30.

Toole, M.J. and R.J. Waldman. 1988. An analysis of mortality trends among refugee populations in Somalia, Sudan, and Thailand. Bulletin of the World Health Organization 66(2): 237-247.

Traub, R.J., I.D. Robertson, P. Irwin, N. Mencke and R.C.A. Thompson. 2004. The prevalence, intensities and risk factors associated with geohelminth infection in tea-growing communities of Assam, India. Tropical Medicine and International Health 9(6): 688-701.

Turshen, M. 1977. The political ecology of disease. Review of Radical Political Economics 9: 45-60.

Wells, S. 2000. Labor, control and protection: the Kahlin aboriginal compound, Darwin, 1911-38. In P. Read (ed.) Settlement: a history of Australian indigenous housing. Canberra: Aboriginal Studies Press. Pp 64-74.

Yang, M.D., J.D. Wang, Y.L. Wang, P.S. Guo, Z.Q. Yoa, P.L. Lu, X.Y. Gu, Y.L. Dong, M.X. Lu and P. Zhu. 1985. Changes in health conditions in the Huainan coal mine in the past three decades. Scandinavian Journal of Work, Environment and Health 11(supp4): 64-67. 